\title{
Experimental and Numerical Investigation of Air Suction in Domestic Gas-Burning Heaters to Increase Efficiency
}

\author{
Peyman Zahedi, S. Mohammad Javadi, Kianoosh Yousefi, and Afshin Pakdel
}

\begin{abstract}
In this paper, the performance of domestic gas burner heating unit is enhanced by optimizing secondary air of combustion that it is controlled by control of area entrance vent of secondary air and the heater second furnace vent. In order to determine the appropriate extent of the area of air suction vent, second furnace vent was closed by experimental methods and a valve with opening and closing capabilities was applied to the under part of the first furnace of the heater and the effect of closing this valve on increasing the heater efficiency was studied. The heating unit is first modeled as a three dimensional physical domain for flow of gases, and conservation equations of mass, momentum, energy, species and radiation are discretized over the meshing system of finite volume method provided in the domain. Experimental set-up to measure and validate the numerical results is equally established. Results show that by closing $84 \%$ of secondary air suction vent and complete closure of the second furnace vent, mass flow rate of air suction becomes $0.0035 \mathrm{~kg} / \mathrm{s}$. In this condition, a $9 \%$ increase in the mean heat transfer rate from furnace surface of the heater will occur.
\end{abstract}

Index Terms-Air suction vent, furnace, gas-burning heater.

\section{INTRODUCTION}

Considering the importance of optimizing fuel consumption and critical proportion of indoor warming in energy consumption, optimizing the structure of indoor gas-burning equipment to increase the efficiency is very important. At the same time, the extent of using indoor gas-burning heaters has multiplied the importance of the studies of optimizing this equipment. Complex geometrical structure, simultaneity of different phenomenon such as combustion, different models of heat transfer (free convection, forced convection and radiation) and also the effect of buoyancy energy in providing combustion air cause weakness in empirical method of try and error to improve the efficiency and highlight the importance of computer simulation. Because of more complete understanding of fluid, heat and combustion processes, using simulation allow us to control these processes toward efficiency and heat transfer improvement.

Considering the applied methods of better combustion with less pollutant and better efficiency of gas-burning heaters, the amount of air which enters the heater and also the amount of air which enters as secondary air has a great effect on heater efficiency and the amount of pollutant. The extent of excessive air suitable for optimum performance of a heater

Manuscript received October 20, 2012; revised February 2, 2013.

Peyman Zahedi, S. Mohammad Javadi, Kianoosh Yousefi, and Afshin Pakdel are with Mechanical Engineering Department, Islamic Azad University, Mashhad Branch, Mashhad, Iran (e-mail: peimanzahedi@gmail.com; $\quad$ mohammad.javadi@gmail.com; kianoosh_py@yahoo.com; afshin.pakdel@gmail.com ). is calculated and also the percent of primary and secondary air of this suitable air for minimum pollution and maximum efficiency is calculated [1].

The effect of parameters such as environment condition, height and diameter of chimney, thermal barriers of furnace and radiation heat transfer ratio and fan installation of the heater on the efficiency improvement have been studied [2]. and meanwhile, the ratio of fuel to utilized air in gas-burn heater has been measured and according to the results the extent of air which flows through a heater set, in normal condition, is almost fourfold of the extent of the required air in stoichiometry mixture which this is significantly effective in decreasing the efficiency of regular gas-burn heaters [3]. The extent of passing flow through an alight heater depends on its design parameters including the area of air entrance into it, so optimizing the heater to sucks adequate air for stoichiometry combustion is important.

\section{HeATER STRUCTURE ORIENTATION}

To optimize the process, first studying a sample heater was done. In Fig. 1 the overall scheme of the heater and its parts are shown. As it can be seen, the heater includes burner, two furnace and chimney which those two furnaces are connected by two cylindrical tubes with $100 \mathrm{~mm}$ diameter.Input fuel is injected through a nozzle into the burner which sucks in some air along with itself which play the role of primary air for combustion. When pre-mixed gas flow enters the first furnace, it ignites. Flame is created and provides its required remained air by the sucked air of first furnace (due to sucking nature of chimney). Combustion products are transmitted to the second furnace by two cylindrical tubes. To allow the increase of the residence time and complete diffusion of consumption products in second furnace, some barriers are put in the way of consumption products into the second furnace entrance vent. After passing the abovementioned barriers, the flow changes its direction towards the chimney entrance vent. Also in this part to prevent quick exhaust of consumption products into chimney a barrier is installed in entrance.

Main task of the second furnace is decreasing the chimney suction impact and minimizing the negative effect of chimney reversed air flow on torch flame stability and its combustion and also decreasing the exhaust speed of the gases derived from combustion and sending increased heat transfer of hot gases into the environment. Bottom part of this furnace is completely opened to release the reversed penetrated flow from the chimney. The suction created in the chimney depends on factors such as: chimney height, chimney area, fume temperature and gases produced from combustion. So by changing each of these above-mentioned 
conditions, the possibilities of reversed suction increase.

\section{METHOD OF EXPERIMENT}

To examine the performance of considered heater and the credibility of the numerical solution, density parameters of combustion products and the temperature of the inner parts of the chimney and also temperature distribution on the heater and furnace external body were measured. Combustion products density and chimney temperature have been measured by using Testo 327 machine. Also surface temperature of the heater and temperature of inside the furnace are measured by using Testo 925 thermometer with contact probe. Steps of the exprimenting are in this way that first the pressure of input gas of the heater is regulated at 178 $\mathrm{mm}$ of water column by using a barometer and then heater is turned on, now we should wait till the heater reach the stable mode which will usually occur after 15 minutes of the start. By stability we mean the time in which the temperature of exhaust combustion products of the heater chimney becomes almost stable, now combustion products are sampled by using gas analyzer. Considered experiments are measured for a chimney with the length of $165 \mathrm{~cm}$.

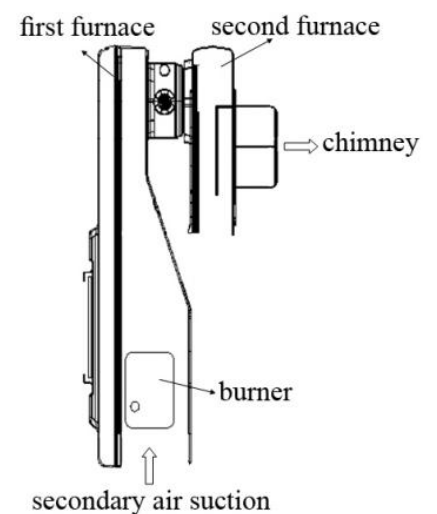

Fig. 1. Overall scheme of heater and its parts

By completely closing the second furnace vent, we begin to gradually close the secondary air entrance vent by the transitive valve which is indicated in Fig. 2. By gradual closure of air entrance vent in every step and after heater stability during considered time with applied suction condition of new air, we measure the extent of $\mathrm{CO}$ and combustion efficiency and combustion products temperature in the chimney.

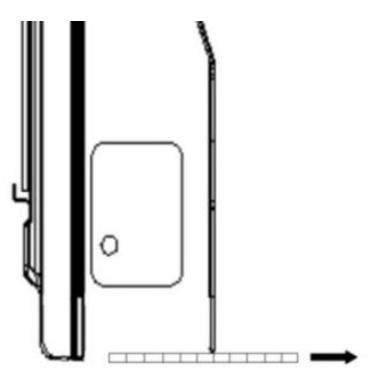

Fig. 2. Transitive valve of furnace suction with opening and closing capabilities

Experimental results as it can be seen from Fig. 9 and Fig. 10 , show combustion efficiency improvement which leads to overall efficiency improvement of the heater that along with efficiency improvement, the increase of exhaust $\mathrm{CO}$ is also evident. This experiment is measured in three modes of low, average and high flame which almost in every three modes results are the same and show increasing pattern of efficiency till the extent of $75 \%$ of air entrance area closure and after that because of the lack of sucked air, cause efficiency drop. But about the extent of exhaust CO till $40 \%$ of air entrance vent closure, the extent of $\mathrm{CO}$ has steady pattern and it can be seen that by more closing the suction vent, more increasing occur in CO pattern which according to OSHA (Occupational Safety \& Health Administration), this extent of CO should be no more than $250 \mathrm{ppm}$.

\section{NumERICAL SOLUTION METHOD}

By using SolidWorks software, geometrical modeling was executed and created model in SolidWorks software is illustrated in Fig. 3.

To exactly study effective parameters of efficiency and heater temperature distribution, Fluent6.3 computational software has been used. The flow inside the considered combustion chamber is of turbulent flow type with density change of chemical materials derived from combustion. Dominating equation on this phenomenon, mass conservation equations, movement, turbulence equations, transmission of species and energy are considered by the assumption of steady with respect of time. To model the expression resulted from turbulence RNG k- $\varepsilon$ method and for modeling combustion flow and calculating transmission of species Eddy-Dissipation method has been used [4].

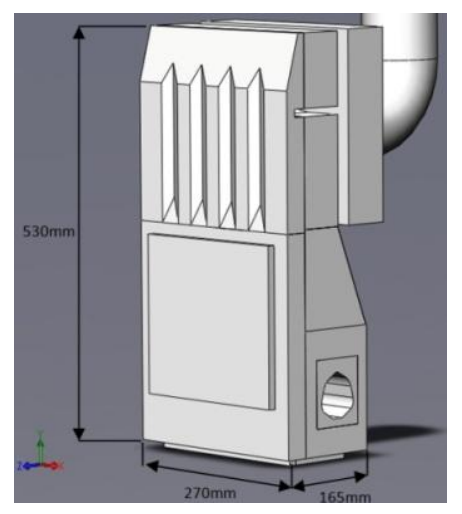

Fig. 3. Created model in SolidWorks software

Equations of transmission of species ( $\mathrm{N}-1$ equations which $\mathrm{N}$ is the number of species) can be expressed as:

$$
\frac{\partial}{\partial x_{i}}\left(\rho u_{i} m_{i^{2}}\right)=-\frac{\partial}{\partial x_{i}} J_{i^{2}, i}+R_{i^{2}}
$$

where

$$
J_{i^{2}, i}=-\left(\rho D_{i^{2}, m}+\frac{\mu_{i}}{S c_{i}}\right) \frac{\partial m_{i}}{\partial x_{i}}
$$

And diffusion factor of species is calculated as follows:

$$
D_{i^{2}, m}=\left(1-x_{i^{2}}\right) / \sum_{j^{1}, j^{1} \neq j^{1}} X_{j^{1}} / D_{i^{1} j^{1}}
$$

And diffusion factor of species is calculated as follows:

$$
\frac{\partial}{\partial x_{j}}\left(\rho u_{i} u_{j}\right)=-\frac{\partial P}{\partial x_{i}}+\frac{\partial \tau_{i j}}{\partial x_{j}}
$$


where tensor stress is

$$
\tau_{i j}=\left[\mu\left(\frac{\partial u_{i}}{\partial x_{j}}+\frac{\partial u_{j}}{\partial x_{i}}\right)\right]-\frac{2}{3} \mu \frac{\partial u_{l}}{\partial x_{l}} \delta_{i j}
$$

Conservation of energy equation in this process with chemical reaction (combustion) is

$$
\begin{aligned}
& \frac{\partial}{\partial x_{i}}\left[u_{i}(\rho E+P)\right]= \\
& \frac{\partial}{\partial x_{i}}\left(\lambda_{e f f} \frac{\partial T}{\partial x_{i}}-\sum_{i^{2}} h_{j^{2}} J_{j^{2}}+u_{j}\left(\tau_{i j}\right)_{e f f}\right)+S_{h}
\end{aligned}
$$

where $S_{h}$ is the source term aroused from the heat released from the chemical reaction, also

$$
E=h-\frac{P}{\rho}+\frac{u_{i}^{2}}{2}
$$

where $h$ is calculated from the ideal gas definition. Effective heat conduction factor, which is heat conduction factor of fluid and turbulence effects on it, with using the RNG k- $\varepsilon$ method calculated as below:

$$
\lambda_{e f f}=\alpha C_{p} \mu_{e f f}
$$

For calculating the turbulence effects on the properties of flow and calculating the effective heat conduction factor and effective viscosity two assistance equations (k- $\varepsilon$ ) has been utilized. Also $\mu_{t}$ is the turbulent viscosity determined from the following equation [5]:

$$
\mu_{t}=\rho C_{\mu} \frac{k^{2}}{\varepsilon}
$$

$C_{\mu}$ is constant factor.

The default values of constant factors for $\mathrm{k}-\varepsilon$ model are:

$$
\begin{aligned}
& C_{\mu}=1.92, \sigma_{\varepsilon}=1.3, \sigma_{k}=1.0 \\
& C_{1 \varepsilon}=1.44, C_{2 \varepsilon}=1.92
\end{aligned}
$$

In this study combustion of methane-air assumed with two stage combustion mechanism as mentioned below [6]:

$$
\begin{array}{ll}
\mathrm{CH}_{4}+1.5 \mathrm{O}_{2} \rightarrow \mathrm{CO}+2 \mathrm{H}_{2} \mathrm{O} & \text { Step } \\
\mathrm{CO}+0.5 \mathrm{O}_{2} \rightarrow \mathrm{CO}_{2} & \text { Step2 }
\end{array}
$$

On the basis of this mechanism, the products of methane oxidization are carbon monoxide and water vapor. In the next stage carbon dioxide formed from carbon monoxide oxidization. Because of complete oxidization of methane in dilute complexes, in combustion with excess air the equation of combustion is expressed as:

$$
\begin{aligned}
& \mathrm{CH}_{4}+\frac{2}{\phi}\left(\mathrm{O}_{2}+\frac{100-\gamma}{\gamma} \mathrm{N}_{2}\right) \rightarrow \\
& \mathrm{CO}_{2}+2 \mathrm{H}_{2} \mathrm{O}+2\left(\frac{1-\phi}{\phi}\right) \mathrm{O}_{2}+\frac{2}{\phi} \frac{100-\gamma}{\gamma} N_{2}
\end{aligned}
$$

In this equation $\phi$ is the ratio of the amount of stoichiometric air to the amount of actual air and $\gamma$ is the oxygen percentage exists in the air, which is $22 \%$ in normal conditions. This equation in bound of $0 \leq \phi \leq 1$ is the governing equation for the complete combustion with excess air. Mass of entrance fuel $\left(m_{f}\right)$ is calculated in terms of fuel heat capacity $(\mathrm{LCV})$, molecular mass $\left(M_{f}\right)$ and gas-burner heat capacity $(\dot{Q})$.

$$
\dot{m}_{f}=\dot{Q} \cdot M_{f} / L C V
$$

which LCV is calculated in terms of enthalpy of combustion products $\left(H_{p}\right)$ and enthalpy of reactants $\left(H_{R}\right)$.

In turbulent flows with chemical reactions Aranius rate of reaction (for laminar flows) or Eddy-Dissipation rate of reaction (for turbulent flows) or both calculated according to the definition of the problem for using in the source term of the transmission of the species equation. In this study rate of reaction is used from Eddy-Dissipation model on the basis of Magnesen \& Hertager, 1976 [7].

\section{GRID GENRRATION AND BOUNDARY CONDITIONS}

One of the most important parts in numerical solving is producing proper geometry of the under studied system which has the least errors in meshing, by considering geometric complexity and numerous intervene parts, a triangular grid has been used for meshing. In the best created grid by Gambit 2.4 software, furnace is divided into 416633 meshes which in Fig. 4 and Fig. 5 you can see solution environment meshing and also defined boundary condition for solving the issue. Considering intense changes of the variables of inside the furnace and particularly near the burner entrance valve, meshes have become smaller than other parts.

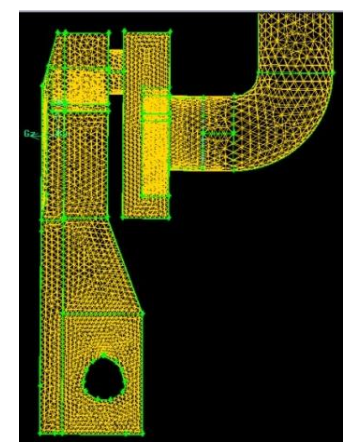

Fig. 4. Solution environment meshing in Gambit software

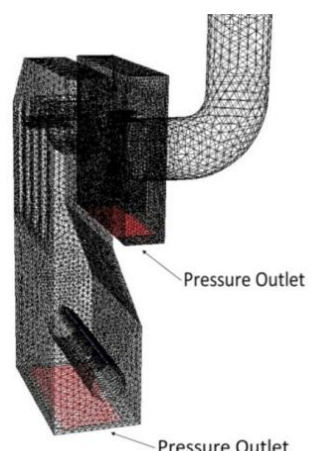

Fig. 5. Applied boundary conditions 


\section{VALIDATION OF NUMERICAL SOLUTION}

To valid and assess the accuracy of numerical solution, temperature distribution on external surfaces of the heater and at some points of the furnace has also been determined by testing. Temperature of furnace upper surfaces and two connecting tubes between furnaces are measured and compared with numerical results. In Fig. 6 temperature distribution of numerical solution on the external body is indicated. In this figure computational temperature distribution is as a constant distribution and measured values in numbers are written on the figure. In Fig. 7. temperature distribution of inside the furnace in a plane right at the center of the furnace is illustrated. Comparison of the results show that obtained temperature change procedure from simulation corresponds very well with experimental data. Also in regard to temperature extent, maximum fault is about $8 \%$.
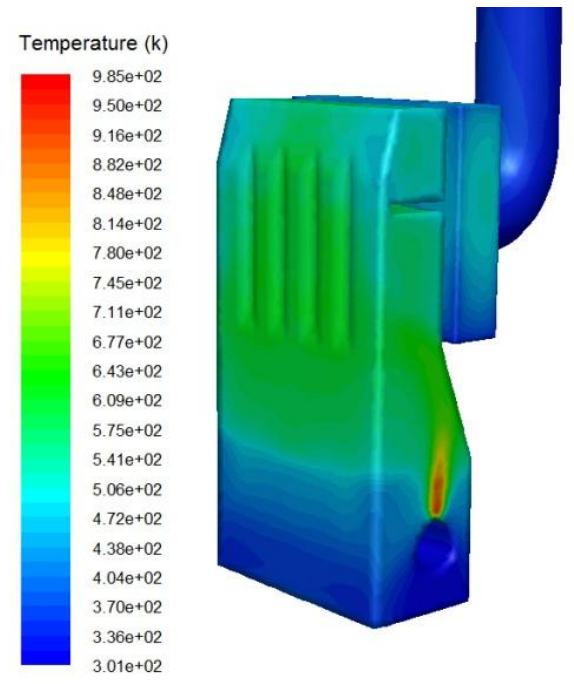

Fig. 6. Temperature distribution of heater furnace body

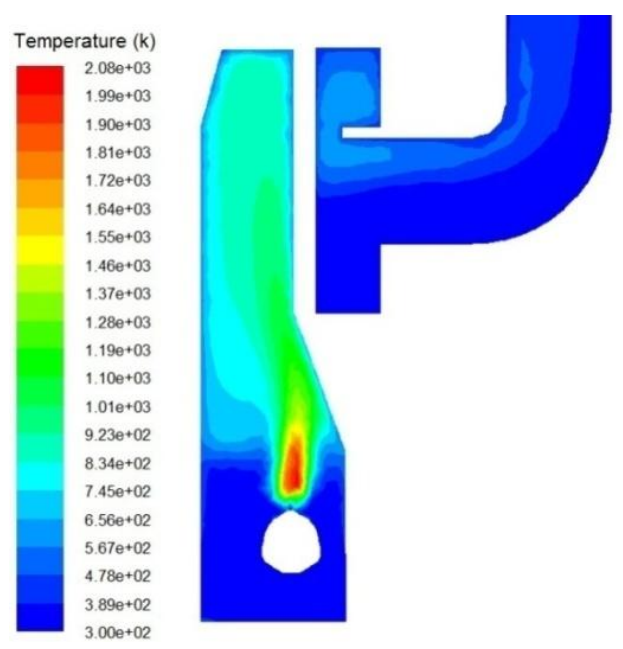

Fig. 7. Temperature distribution of inside the furnace

\section{NUMERICAL SOLUTION RESULTS}

By examining input air rate from bottom part of the furnace, as it is seen in Fig. 8, it can be concluded that by closing the vent of the second furnace input air rate from secondary air suction vent increase and by closing completely of second furnace cent mass flow rate of air suction increase by $71 \%$ because of chimney suction effect.
By complete closure of second furnace vent, as it can be seen from Fig. 11 and Fig. 12 , when $84 \%$ of secondary air entrance vent is closed and the extent of sucked air and needed air for complete and stoichiometric combustion are approaching each other, we will have $9 \%$ increase in mean heat transfer of furnace bodies and then by more closing of air suction vent because of the lack of input air and creation of incomplete combustion, heat transfer rate has been decreased.

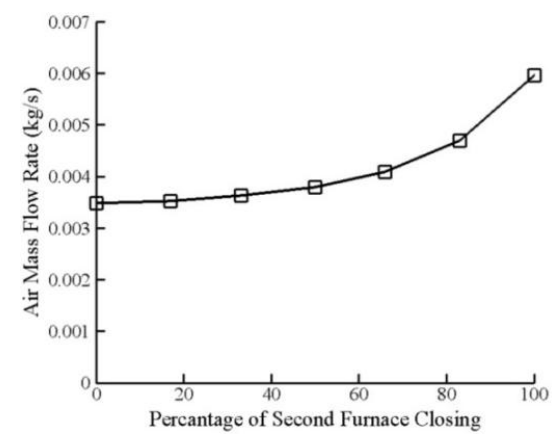

Fig. 8. Examining the impact of the area of second furnace vent on mass rate of sucked air

As it is shown in Fig. 12, the temperature of combustion products and heat transfer rate relative to the area of air suction vent have been increased and in the condition of $84 \%$ closure air suction vent, combustion products have the highest temperature and then temperature of combustion products in chimney decrease because of incomplete combustion and lack of needed air, and as the same reason mass fraction of $\mathrm{CO}$ in numerical method after $78 \%$ closing of air suction area increase as it is seen in Fig. 10.

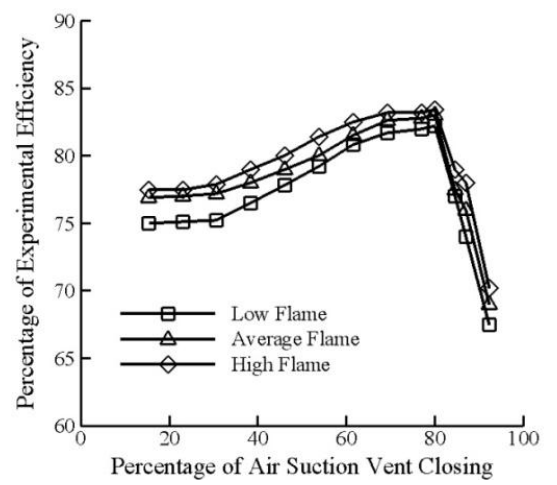

Fig. 9. Investigation of extent the area of air input to combustion efficiency in three modes of low, average and high flame

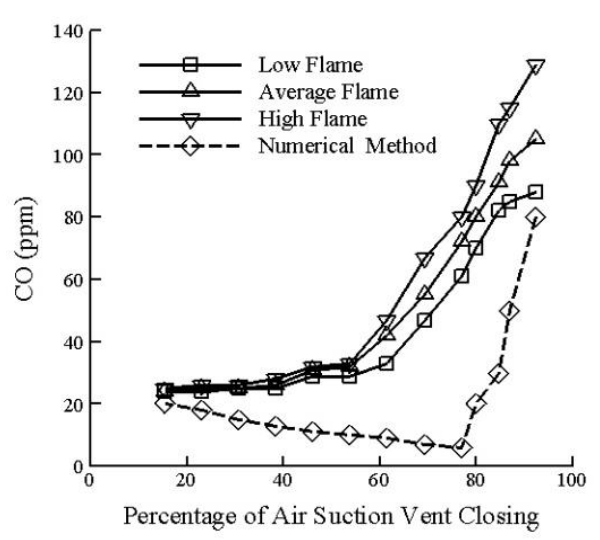

Fig. 10. CO density diagram in chimney resulted from combustion relative to the closure of air suction vent 


\section{CONCLUSION}

By considering the extent of using indoor gas-burn heaters and the importance of optimizing fuel consumption in them, this paper has presented experimental and computer simulation of a regular heater. First to ensure the accuracy of modeling, heater with current geometry modeled and analyzed and results of numerical simulation have been compared with results of experiment.

With the purpose of increasing the efficiency, we began to close the second furnace vent and also the valve of secondary air suction in the bottom part of the furnace by experimental method where more closures of suction valve increases the combustion efficiency.

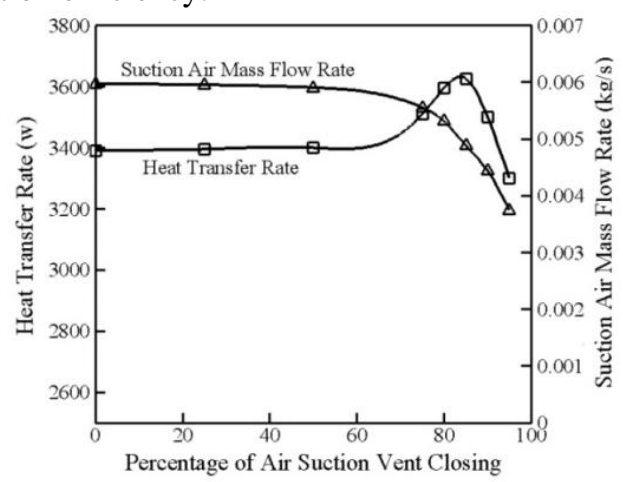

Fig. 11. Examining the impact of the area of air entrance vent on mass flow of sucked air and heat transfer rate of furnace body

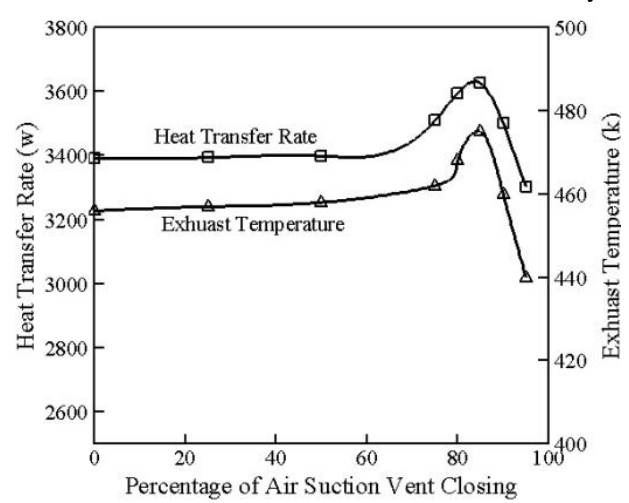

Fig. 12. Examining proportion of external surface of suction valve to the temperature of combustion products in chimney and temperature transfer rate from furnace surface

In numerical simulation, as it is indicated by diagrams, it can be seen that heat transfer rate increases by the closure of air suction vent where by $84 \%$ closure of suction valve mass rate of entering air equals the heater primary mode during production but is accompanied by $9 \%$ increase in mean heat transfer rate of the heater furnace surface. Because of the limitations in complete closure of the second furnace due to safe exhaust of reverted gas from chimney, recommendation for further works is to choose a mechanism in the second furnace that the vent can be open whenever the exhausted gases revert from chimney to the furnace and come out from this open vent to prevent reversed gas flows effect on torch flame stability. This condition leads to increase in the heat transfer rate of heater furnace and accordingly heater efficiency improvement.

\section{NOMENCLATURE}

$\begin{array}{ll}\rho & \text { Density } \\ \mu & \text { Viscosity } \\ u & \text { Velocity } \\ P & \text { Pressure } \\ E & \text { Internal energy } \\ H & \text { Enthalpy } \\ T & \text { Temperature } \\ \gamma & \text { Oxygen percent } \\ \phi & \text { Ratio of stochiometric air to actual air } \\ \tau_{i j} & \text { Tension tensor } \\ \sigma & \text { Stephan-Boltzman constant } \\ \sigma_{s} & \text { Propagation constant } \\ S & \text { Path length } \\ \vec{s} & \text { Radiation direction vector } \\ \delta_{i j} & \text { Kronecker delta } \\ \vec{r} & \text { Location vector } \\ I & \text { Radiation intensity } \\ \dot{Q} & \text { Heat capacity of the gas-burner } \\ \Phi & \text { Phase function } \\ \Omega^{\prime} & \text { Body surface angle }\end{array}$

\section{REFERENCES}

[1] M. Bidabadi, M. Seddighi, and S. Yousefi, "Optimizing gas-burn heater," in Proc. Second conference of Iran combustion, 2006.

[2] A. Kianifar, H. Moein, M. Javadi, and A. RashidiToroghi, "Numerical simulation of combustion in an indoor gas-burn heater and examining effective parameters of that," in Proc. Fifteenth annual conference of mechanic engineering, Iran, 2006.

[3] M. Rahimi and V. AbdiAghdam, "Estimating the proportion of fuel to used air in a gas-burn heater set," in Proc. Second conference of Iran combustion, Islamic Azad University of Mashhad, Iran, 2006.

[4] D. C Howarth, "A PDF method for turbulent mixing and combustion on three-dimensional unstructured deforming meshes," Int. J. Engine Res, 2000, vol. 1, pp. 171-190.

[5] M. Muradoglu, S. B Pope, and D. A. Caughey, "The hybrid method for the PDF equation of turbulent reacting flows: consistency conditions and correction algorithms," J. Comput. Phys, 2001, vol. 172, pp. 841-878.

[6] F. L. Dryer and I. Glassman, "High temperature oxidation of CO and $\mathrm{CH}_{4}$," in Proc. Fourteenth Sym. Int. on Combustion, 1973, pp. 987-1003.

[7] B. F. Magnussen and B. H. Hjertager, "On mathematical models of turbulent combustion with special emphasis on soot formation and combustion," in Proc. 16th Int. Symposium on Combustion, Philadelphia, 1976.

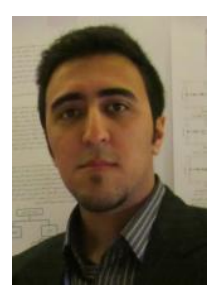

Peyman Zahedi was born in 1987, Iran. He received B.Sc. degree in mechanical engineering the field of Auto-Mechanic from Khayyam university of Mashhad, Mashhad, Iran in 2008 with high distinction. Currently he is M.Sc. student (final semester) in Azad University of Mashhad and studied mechanical engineering the field of energy conversation with great distinction. His research interests include Fuel and Combustion, Heat transfer, Multiphase Flows Simulation , Boundary Layer Control, Boundary Layer Theory, Fluid Mechanics, Turbulent Flows and Modeling. Some of the most important paper titles that presented in ICMEAT 2012 conference which held in Isfahan, Iran are "A Review of Multiphase Flows Simulation Methods", "Investigation for increase or decrease the lift and drag coefficient on the airfoil with suction and blowing", "Numerical investigation on the flame speed of CH4/Air diluted with $\mathrm{CO} 2$ and vapor", "Incompressible fluid flow on a circular cylinder with heat transfer by finite element method" and "Incompressible fluid flow on four elliptic cylinder by finite element method". 